\title{
Evaluation on Snow Infiltration into Heating Ventilation and Air Conditioning Intake: A Numerical Study
}

\author{
Jan Potac and Thomas K. Thiis \\ Department of Mathematical Sciences and Technology, Norwegian University of Life Sciences, As 1432, Norway
}

\begin{abstract}
A HVAC (heating ventilating and air conditioning) system is generally designed to ventilate an indoor space. In windy and snowy climates dispersed snow particles in ambient air can enter the intake duct, potentially causing a serious problem. The study addresses the influence of suction volumetric flow rates, the potential discrepancy of snow intake based upon the wind direction in relation to the intake vent, and the possible difference in amounts of infiltrated snow particles in varying intake vent design and locations. The necessary characteristic quantities are defined. The simulation results show the rate of infiltration and the efficiency of the chosen intake designs. The magnitude and direction of wind influences snow infiltration significantly. The daily amount of infiltrated snow is introduced to be the characteristic measure of the infiltration in design of the HVAC systems.
\end{abstract}

Key words: Snow, infiltration, intake, HVAC, CFD (computational fluid dynamics).

\section{Introduction}

HVAC (heating ventilating and air conditioning) system has become a common part of a building. It is widely used in large buildings such as shopping malls, commercial and industrial buildings, etc., where heat loads and fresh air demand may be large due to present technological processes and high occupancy. Recently, the use of HVAC systems has increased in residential houses. The main purpose of a ventilation system is to distribute fresh air inside a building, in accordance with several health and safety criteria. Good indoor environmental quality is one of the fundamental needs.

Ambient air, commonly used in ventilation, is often contaminated by dust and bio-aerosols. As ambient air pollution increases due to traffic, industry, etc., the need for efficient treatment increases as well. One of the most common and basic treatments is the filtering of air borne particles inside HVAC unit. In addition, the atmospheric water content is another potential pollutant. Water in the form of moisture, rain droplets or ice particles can be captured on ducting surface or

Corresponding author: Jan Potac, Ph.D., research fields: snow, transport of snow, snow loads and ventilation. E-mail: jan.potac@gmail.com. inside the filter and consequently affect its function. It may result in mold growth and can pose a hazard of potentially serious health problems. The importance of clean and dry outdoor intakes is generally known [1].

The rate of infiltration of rain droplets and snow particles into a HVAC system is primarily conditioned by the local climate. The area of generally higher amount of water precipitation is expected to be more exposed to moisture-infiltration-related problems. The rate of infiltration of rain or snow particles depends on several factors such as particle properties, wind velocity, particle density distribution, design and orientation of the intake, and the overall aerodynamics of the building. The HVAC unit is usually placed on the roof or inside the building with the suction ducting connected to ambient air. An intake is usually covered by a screen and oriented upstream the most common wind direction of the site.

Although service staff of a building or HVAC system is often faced to snow infiltration into intakes, there has been only a few works published according to authors' knowledge. Some work was done in Finland and noted that snow infiltration caused serious problem of $10 \%$ of the studied HVAC systems [2]. 
There are a few methods to prevent rain and snow particles infiltration into the intake. The most common protection installed on an intake is a rain screen or mechanical louvers. Although the blades of such screen are sufficient enough to stop rain droplets, the relatively light snow particles can still easily enter the intake and consequently accumulate inside. The snow captured on a filter does facilitate a drop in pressure in the filter once a predetermined threshold value of the control system evaluates a failure and the filter is consequently replaced. In many cases, the captured snow partially melts inside the ducting and leaves the ventilation system through a drainage system. In some mechanical louvers electric heating devices are also used which melt the snow and increases louver's prevention efficiency for snow. Pre-filters are also applied to protect ventilation systems from snow penetration. There is another snow removal method that entails the usage of a sedimentation room. The special inner arrangement of the room deflects the flow and separates particles from the flow. This concept was first tested and validated in a wind tunnel [3]. Also, another solution to decrease the snow infiltration has been introduced. It has been shown that a deflector placed in front of an intake reduces snow particle infiltration [3, 4]. It has been concluded that a deflector in front of the inlet will prohibit direct exposure to the impinging snow particles and decrease the snow penetration into the inlet.

The European Standard EN 13030:2001 "Ventilation for buildings-Terminals-Performance testing of louvers subjected to simulated rain" helps by providing a useful classification method. It introduces four classes of the rain defense classification in a relation to range of the rain defense effectiveness, and also actual rain entry rate. Although this methodology has been used by several louvers manufactures, there does not exist any classification related to snow infiltration.

CFD (computational fluid dynamics) is a design tool which has been used in many industrial applications including HVAC applications. When it comes to design and layout of a specific intake opening, one can use simple hand calculation or more advanced CFD-simulation tools. In case of air intakes, the numerical simulation allows one to assess the wind flow characteristics that influences the snow infiltration. Similar analysis can also be performed using wind tunnel techniques although the numerical simulation has the advantage of performing tests to scale and flow fields can be reviewed without repeating the tests. Although the necessary guidelines, recommendations and calculation methods have been introduced, in real life situations problems frequently occur.

\section{Location and Design of an Air Intake}

The national standards usually provide several advices for proper intake location. In general, the standards recommend that outdoor air devices shall be located in such a way that the outdoor air entering the building is as clean as possible. For example, some instructions for location of the intakes have been given in Finish building code [5]. Regarding to rain and snow infiltration, it says that outdoor air devices and their connections to the ventilation system and the building shall be located, protected and designed in such a way, or the construction of the outdoor air device shall be such that no harmful quantities of snow or rainwater will enter the ventilation system. In case rainwater or snow may gain access to ventilation chambers or ducts, suitable drainage should be provided. Any snow or rainwater that enters the system shall not cause damage to the building or the ventilation system or negatively influence the operation of the ventilation system.

Also, EN 13779:2007 [6] provides some other recommendations, e.g., no air intake should be positioned just above the ground. A distance of $3 \mathrm{~m}$ (or at least 1.5 times the maximum expected thickness of snow) between the bottom of the intake and the ground is recommended. On top of the building or when the concentrations on both sides of the building are similar, 
the intake should be arranged on the windward side of the building. Wherever, the risk of penetration of water in any form (snow, rain and mist, etc.) or dust (including leaves) into the system is apparent, an unprotected opening should be dimensioned for a maximum air velocity in the opening of $2 \mathrm{~m} / \mathrm{s}$. The height of the bottom of an air intake opening over a roof or deck should be at least 1.5 times the maximum yearly expected thickness of snow. The distance can be lower if the formation of a layer of snow is precluded by means of, for example, a snow shield.

The fall velocity of the snow particle is generally low, approximately between $0.2 \mathrm{~m} / \mathrm{s}$ and $1.0 \mathrm{~m} / \mathrm{s}$. However, Mellor [7] refers to several authors who evaluated fall velocity of different snow crystal types. The low fall velocity allows that the snowflakes drift easily into the HVAC system if the face velocity is too high in the air intake. Because of the low fall velocity the prevention of the snow penetration is more difficult than the rainwater penetration and it is recommended that the face velocity of the outdoor air shall be below $1 \mathrm{~m} / \mathrm{s}$. However, the maximum face velocity of the outdoor air on the intake shall not exceed $2 \mathrm{~m} / \mathrm{s}$ as mentioned before, according to standards $[5,6]$. If an intake is located just above roof or ground, the snow will be driven to the system more easily. A proper location higher from the roof or ground levels prevents snow entrance. Also the wind shelters and fences could be used against the drifted snow.

Good placements for air intakes are in inner yards of the building because the wind speed is typical lower than on outer facades. Also other buildings and plants, especially conifers, decrease the wind speed. The effect of the wind pressure could be reduced also with the wind shelters. The wind shelters shall be dimensioned wide enough or they shall be open only from bottom so that wind could not directly blow to the air intake. When the wind shelter is used it is important that the opening of the outdoor air intake is wide enough so that the air velocity and pressure at the opening is not too high [2].

\section{Case Study}

Wind conditions during an operation of a HVAC system varies and changes suddenly. The wind speed and direction may affect rate of snow infiltration into the intake. Also, the surrounding of an intake may influence its performance. Therefore, the snow infiltration is to be studied on combination of two cases of intake locations on a building with two different headings of the intake.

Firstly, the HVAC unit is considered to be installed stand-alone on a flat roof. This can be visualized as a box (HVAC unit) elevated above a flat surface. There are two orientations considered: intake headed upwind, i.e., windward (W), or downwind, i.e., leeward (L). Sometimes the overall design of a building does not allow such stand-alone placements of HVAC units on the roof. Thus, the HVAC unit is placed inside a special room and the intake might be part of a building facade. The effect of the immediate surrounding is studied on windward or leeward facade of a building. Location of both intake arrangements is shown in Fig. 1a.

As mentioned before, intakes are commonly covered by a screen or louvers. Since the aim of the study is to define basic characteristic behavior of various intake geometries the intake is considered to be without any screen or louver. The influence of such simplification is to be discussed later. There are three intake designs considered: free (F), overhang (O) and elbow (E). In addition, an external flow deflector (D) placed in front of the intake is to be applied in the case of stand-alone case. The schematic drawing of considered intake designs is shown in Fig. 1b. The operational conditions of the HVAC unit are characterized by the air mass flow rate varying between $10 \times 10^{3} \mathrm{~m}^{3} / \mathrm{h}$ and $28 \times 10^{3}$ $\mathrm{m}^{3} / \mathrm{h}$. This flow rate range is applied on each intake design and location, while the approaching wind conditions (direction and magnitude) vary.

\section{Methodology}

To calculate the snow distribution inside the domain, the general purpose Ansys CFX 12.1 finite volume 


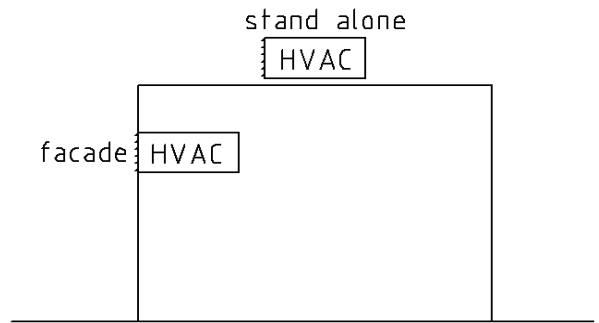

(a) Arrangement on a building

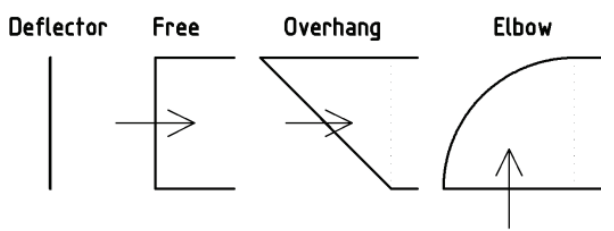

(b) Intakes: free (F), overhang (O), elbow (E)

Fig. 1 Location and geometry of an intake.

code was applied. The two phase flow is solved using Euler-Euler approach. Both the air and the snow phases pose their own flow field where the fluids interact vis-a-vis the drag force as calculated using the Schiller-Naumann drag model. The code solves steady, incompressible, time averaged Navier-Stokes equations, using $k$ - $\omega$ turbulence model to close the system of equations. In general, the flow characteristics of solid particles in a gas-solid suspension vary significantly with the geometric and material properties of the particle. The geometric properties, e.g., particle size, size distribution and shape, which all affect particle flow behavior through an interaction with the gas medium as exhibited by the drag force, the distribution of the boundary layer on a particle surface, and the generation and dissipation of wake vortices [8].

The stokes number is a very important parameter in fluid-particle flow. It is defined as:

$$
S t=\frac{\tau_{V}}{\tau_{F}}=\frac{\rho_{d} d_{d}^{2} u_{c}}{18 \mu_{c} L}
$$

where, $\tau_{V}$ and $\tau_{F}$ is the momentum response time and some characteristic time of the field, $\rho_{d}$ is the density of snow particle, $d_{d}$ is the particle diameter, $u_{c}$ is the flow velocity, $\mu_{c}$ is the viscosity of air, and $L$ is a characteristic dimension. Table 1 shows calculated values of stokes number considering a particle of given properties carried by the wind of $2 \mathrm{~m} / \mathrm{s}$ and passing a wall of $1 \mathrm{~m}$ height. It can be recognized that for particles of small diameter the stokes number is smaller than 1 . Thus, the particle and fluid velocities are nearly equal.

Due to the variety in inlet wind conditions, normalizing the HVAC air velocity is beneficial. The mean air velocity at the HVAC outlet, $u_{\text {mean,HVAC }}$ calculated from volumetric flow rate can be normalized by dividing by the wind speed, $u_{\text {wind }}$ at the domain inlet. The NAV (normalized air velocity) is then calculated as:

$$
N A V=\frac{u_{\text {mean }, H V A C}(\mathrm{~m} / \mathrm{s})}{u_{\text {wind }}(\mathrm{m} / \mathrm{s})}
$$

The amount of the snow infiltrating into the intake can be expressed by IR (infiltration ratio). It can be defined to be the ratio of the snow flux inside the duct to the upwind snow flux expressed as:

$$
I R=\frac{\text { snowflux }_{\text {duct }}\left(\mathrm{kg} / \mathrm{m}^{2} \mathrm{~s}\right)}{\text { snowflux }_{\text {ref }}\left(\mathrm{kg} / \mathrm{m}^{2} \mathrm{~s}\right)}
$$

The upwind or reference snow flux is taken from the plane located at the domain inlet. Both the reference plane and duct are considered to occupy the same area, i.e., the cross-section of the duct. The kinematics, or particle interaction of snow particles, is assumed to not affect the main air flow because of low concentration of particles. Using this assumption the value of IR expresses the amount of infiltrated snow regardless to the snow concentration in the ambient air.

Useful parameter to assess the snow infiltration can be the efficiency of the intake to resist particles to infiltrate. Therefore, RSRE (relative snow removal efficiency) has been introduced as:

$$
R S R E=1-\frac{I R_{\text {intake }}}{I R_{\text {ref }}}
$$

Table 1 Stokes number.

\begin{tabular}{llll}
\hline & \multicolumn{2}{c}{$\rho_{d}\left(\mathrm{~kg} / \mathrm{m}^{3}\right)$} \\
\cline { 3 - 4 } & & 50 & 890 \\
\hline$d(\mathrm{~mm})$ & 0.05 & 0.00085 & 0.015 \\
& 5 & 8.5 & 152 \\
\hline
\end{tabular}


where, $I R_{\text {intake }}$ and $I R_{\text {ref }}$ is the snow infiltration ration of the particular intake and reference intake, respectively.

\section{Validation}

This computational method to evaluate the rate of infiltrated snow particles into ventilation opening was successfully applied and compared with wind tunnel measurements [9]. The study was conducted using artificial snow particles generated by a snow gun. Although such particles differ from those which occur during natural snow fall, the same setup of the model is attempted to keep the validity. The different particle properties would require re-evaluation since connected to drag model, etc.. Also, no such experimental are available thus decided to keep already tested model setup.

\section{Numerical Model}

\subsection{Geometry and Mesh}

The simplified HVAC unit has the dimensions of 1.5 $\mathrm{m} \times 1.5 \mathrm{~m} \times 5 \mathrm{~m}$. As mentioned before, there are three intake designs considered in two locations on the building: stand-alone and as a part of the facade. The stand-alone case is elevated approximately $2 \mathrm{~m}$ above the roof. For the other placement of the HVAC unit, i.e., on the facade the simple cube building of a side of $15 \mathrm{~m}$ is considered. The intake is located in the center of the facade.

The domain inlet is located approximately $20 \mathrm{~m}$ and $70 \mathrm{~m}$ upwind the particular inlet in case of stand-alone and facade inlet, respectively. The three-dimensional domain is simplified using a vertical symmetry plane in the flow direction. The domain consists of approximately $600 \mathrm{k}$ tetrahedral cells. The inflation layer of five layers and $2 \mathrm{~cm}$ total thickness is built on all wall boundaries.

\subsection{Model Setup and Boundary Conditions}

In the numerical model, the artificial snow with density of $300 \mathrm{~kg} / \mathrm{m}^{3}$ and particle diameter $0.15 \mathrm{~mm}$ is used. It is noted that snow particles in natural precipitation usually have a lower density and a higher particle diameter [7]. The air is considered to be ideal gas at the temperature of $-10{ }^{\circ} \mathrm{C}$.

The flow field is driven by the pressure difference between the domain inlet and outlet, and by the gravity force acting on snow particles. In the case of stand-alone intake, two characteristic constant wind speeds at the domain inlet are considered. The inlet wind speed is set to the value of $2 \mathrm{~m} / \mathrm{s}$ or $10 \mathrm{~m} / \mathrm{s}$. These values represent breezes in windy conditions during a snow event. In the case of facade intake, the domain inlet velocity follows logarithmic law expressed as:

$$
u_{\text {wind }}(z)=\frac{u_{*}}{\kappa} \ln \left(\frac{z}{z_{0}}\right)
$$

where, $u_{\text {wind }}(z)$ is the wind speed at a given height $z$, $u_{*}$ is the friction velocity, $\kappa$ is the von Karman's constant equal to 0.41 and $z_{0}$ is the aerodynamic height of the roughness elements. In the simulations, the logarithmic wind profile is built using a reference wind speed of $8 \mathrm{~m} / \mathrm{s}$ at height of $10 \mathrm{~m}$, and aerodynamic roughness height of $0.08 \mathrm{~m}$.

The vertical snow mass concentration at the inlet is considered to be uniform since the inlets are elevated high enough to be influenced by saltating snow particles. The snow particle concentration of 0.0045 $\mathrm{kg} / \mathrm{m}^{3}$ was chosen. It corresponds to a snow concentration at $1 \mathrm{~m}$ height using the snow concentration profile expression [9] as:

$$
c_{\text {snow }}(z)=0.004 z^{-0.901}
$$

Nevertheless, the influence of the snow concentration on the resulting infiltration is omitted using the dimensionless IR. The HVAC unit outlet is defined using the mass flow value corresponding to operational conditions.

\section{Results}

\subsection{Study Case 1: Stand-Alone Intake}

The simulation results for domain inlet wind velocity of $2 \mathrm{~m} / \mathrm{s}$ are plotted in Fig. 2. Regression analysis of the discrete data points results in several 
linear functions. This corresponds to the stokes regime, i.e., $S t \leq 1$, where particles easily follow the fluid flow.

Using this NAV (normalized air velocity), it can be seen that for the free, windward (F, W) case both the IR and NAV values are equal to 1 for air volumetric flow rate of $16 \times 10^{3} \mathrm{~m}^{3} / \mathrm{h}$ which corresponds to the mean air velocity of $2 \mathrm{~m} / \mathrm{s}$. This can be re-interpreted to be a balance or unity between airborne snow and snow particles captured by the intake. The F, W linear function also shows that any change in the volumetric flow rate will result in the same change of IR. Considering the F, W case to be the idealized reference, the IR of any single intake can be normalized and expressed relatively to this reference state. Any change in the value of IR with regard to the used shield can be expressed by the RSRE defined in Eq. (4).

Table 2 shows RSRE in relation to air volumetric flow rate at the HVAC outlet. It can be seen that for high flow rates the RSRE values are not as large as for low flow rates.

Fig. 3 plots the results for wind velocity of $10 \mathrm{~m} / \mathrm{s}$.
The data points can be fit into line functions using regression analysis. In this case, the ambient wind velocity is much higher than the mean air velocity at the HVAC outlet. The difference between leeward and windward location is higher compared to the case in Fig. 2. It can be understood that in strong wind the air and snow particles have high momentum and are less susceptible to sudden change in flow direction.

Table 3 shows RSRE values for wind speed of 10 $\mathrm{m} / \mathrm{s}$. The effect of leeward position is much higher than the case of wind speed of $2 \mathrm{~m} / \mathrm{s}$. Tables 2 and 3 show that the application of the flow deflector in front of the intake reduces the snow infiltration significantly, mainly for high wind velocity, i.e., $u_{\text {wind }}=10 \mathrm{~m} / \mathrm{s}$.

\subsection{Study Case 2: Facade Intake}

The obtained values of IR fitted using linear regression are plotted in Fig. 4. The dense lines show small relative difference between single intakes. At low flow rates, the elbow shield is more efficient than overhang on windward side, while on leeward the

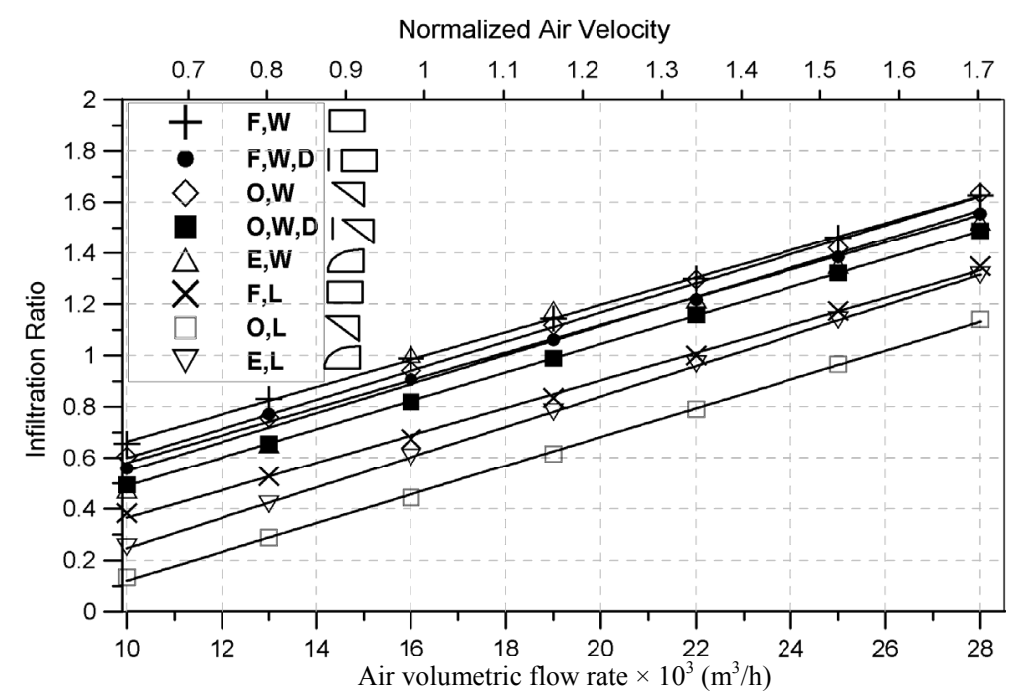

Fig. 2 Stand-alone intake, $u_{\text {wind }}=2 \mathrm{~m} / \mathrm{s}$.

Table 2 Relative snow removal efficiency: stand alone intake, $u_{\text {wind }}=2 \mathrm{~m} / \mathrm{s}$.

\begin{tabular}{|c|c|c|c|c|c|c|c|c|}
\hline Intake arrangement & & & & & & 4 & 4 & 4 \\
\hline Air flow rate $\left(\mathrm{m}^{3} / \mathrm{h}\right)$ & \multicolumn{8}{|c|}{ Relative snow removal efficiency (-) } \\
\hline 10,000 & 0.00 & 0.10 & 0.17 & 0.13 & 0.26 & 0.45 & 0.82 & 0.63 \\
\hline 16,000 & 0.00 & 0.04 & 0.10 & 0.08 & 0.16 & 0.30 & 0.54 & 0.39 \\
\hline 28,000 & 0.00 & 0.00 & 0.03 & 0.05 & 0.08 & 0.18 & 0.30 & 0.19 \\
\hline
\end{tabular}




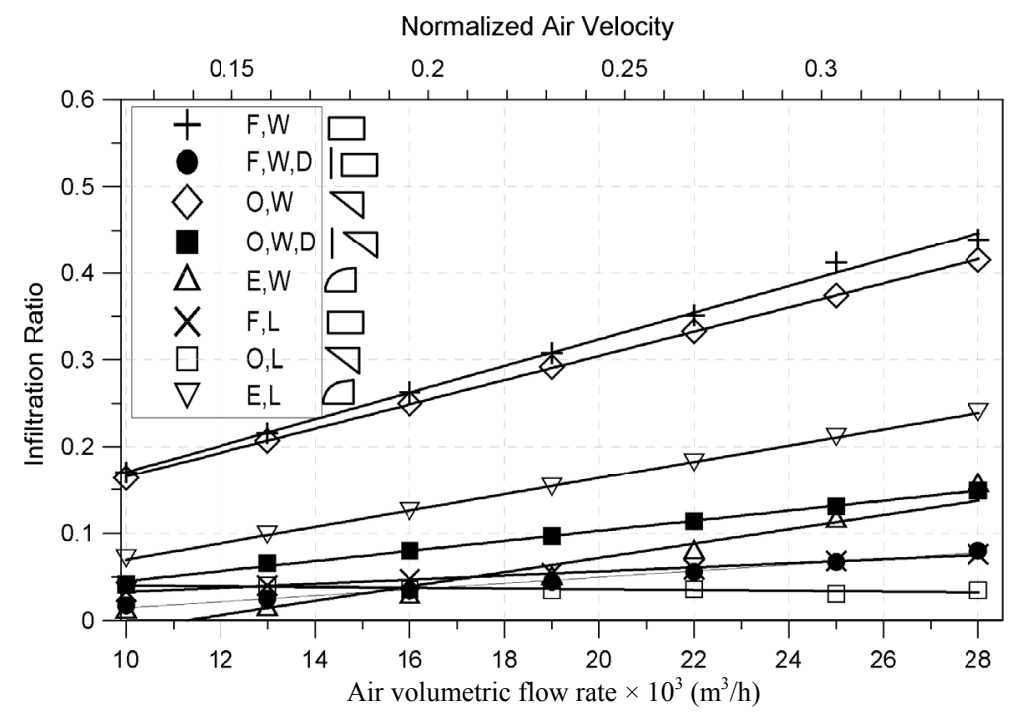

Fig. 3 Stand-alone intake, $u_{\text {wind }}=10 \mathrm{~m} / \mathrm{s}$.

Table 3 Relative snow removal efficiency: stand alone intake, $u_{\text {wind }}=10 \mathrm{~m} / \mathrm{s}$.

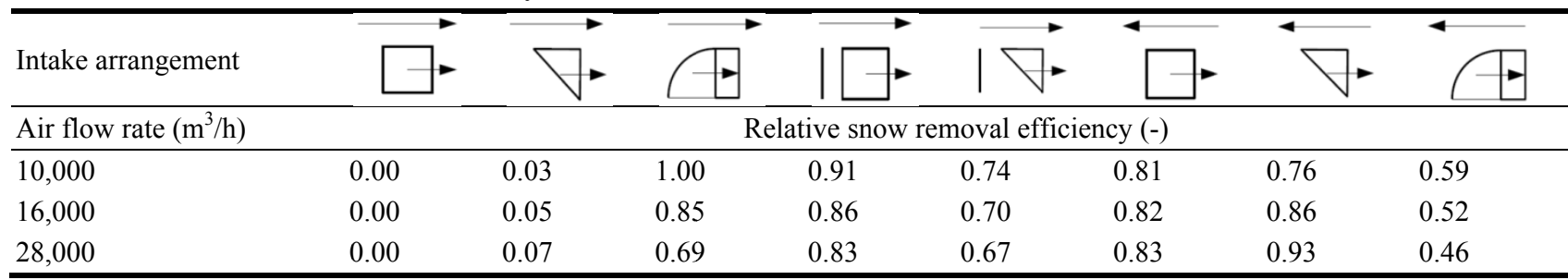

overhang captures more snow than the reference free intake. The leeward application of any shield for high flow rates has little effect. Table 4 summarizes the RSRE normalized to the free inlet on windward and leeward side, respectively. It can be seen that for high flow rates the RSRE values are not as large as for low flow rates.

\section{Discussion}

\subsection{Study Case: Stand-Alone Intake}

In Fig. 2, it can be seen that for windward position, the highest IR appears in the case with free inlet followed by overhang shield. The lowest value of IR is obtained for elbow shield.

The leeward position of the free inlet shows highest value of IR, whereas the elbow shield shows higher value of IR than the overhang. This behavior is observed for both of the wind velocities, as shown in Tables 2 and 3 . The difference in intake particle entrainment for leeward overhang and elbow shield is shown in Fig. 5. It can be observed that the elbow shield lifts or captures the particles from the flow below the opening up into the HVAC, whereas the orientation of the opening of the overhang shield prevents particle transport into the intake. In addition, the dependency of RSRE on volumetric flow rate show that in theoretical infinitely high flow rates all the snow particles enter the intake regardless to actual design. The effect of leeward position of the intake for low flow rates is significant.

All values of IR obtained from simulations are positive whereas the approximation returns, in some cases negative values of IR, as shown in Table 3 . If IR of an intake is higher than IR of the reference intake, Eq. (3) then gives negative values of RSRE. In other words, the chosen intake captures more snow than the reference intake. Any value of RSRE larger than 1 or negative is physically impossible. When linearizing the data points, this failure might occur due to incorrect interpolation. Therefore all negative values should be 


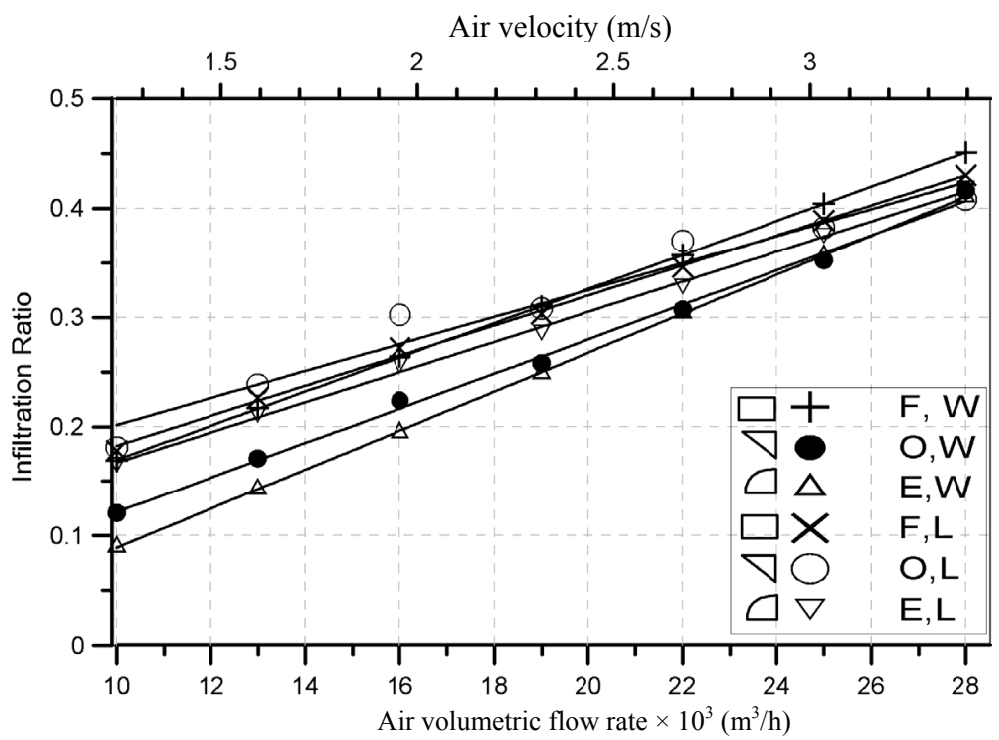

Fig. 4 Facade intake.

Table 4 Relative snow removal efficiency: facade intake.

\begin{tabular}{|c|c|c|c|c|c|c|}
\hline Intake arrangement & & & & 4 & 4 & \\
\hline Air flow rate $\left(\mathrm{m}^{3} / \mathrm{h}\right)$ & \multicolumn{6}{|c|}{ Relative snow removal efficiency (-) } \\
\hline 10000 & 0.00 & 0.28 & 0.47 & 0.00 & 0.00 & 0.08 \\
\hline 16000 & 0.00 & 0.18 & 0.25 & 0.00 & 0.00 & 0.06 \\
\hline 28000 & 0.00 & 0.10 & 0.09 & 0.00 & 1.00 & 0.03 \\
\hline
\end{tabular}

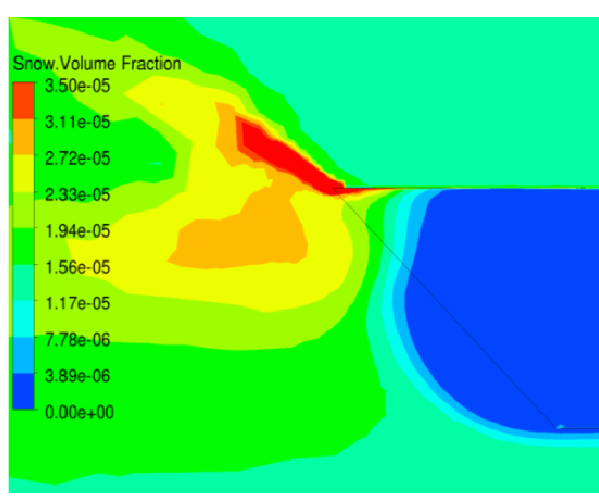

(a) Overhang

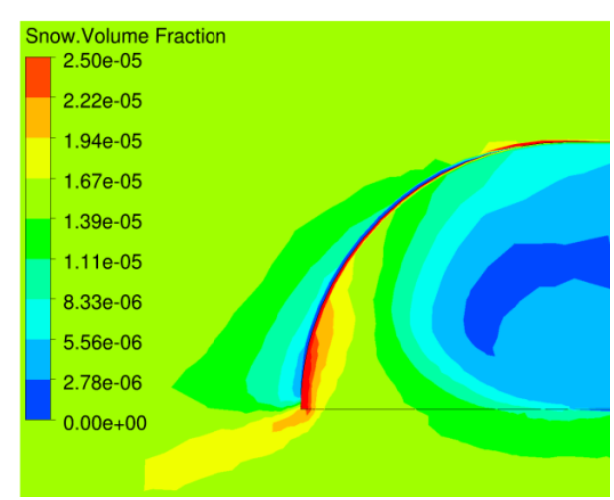

(b) Elbow

Fig. 5 Snow volume fraction: leeward.

set to zero and values higher than one should be set to one.

It can be stated that at high wind speeds the overall aerodynamics of an intake and its orientation becomes an important factor influencing the IR. This can be seen on the elbow shield shown in Fig. 6. The windward case is characterized by the wake formed on the leading edge. The wake affects the general air flow pattern of the intake. The size of the wake is influenced by the magnitude of the approaching wind and the volumetric flow rate at the HVAC outlet. The size of a wake formed from the leading edge in various conditions is shown in Fig. 6. The wake is depicted using snow volume fraction. The region with low value of snow volume fraction corresponds to the appeared wake. It can be observed that the increased volumetric flow rate 


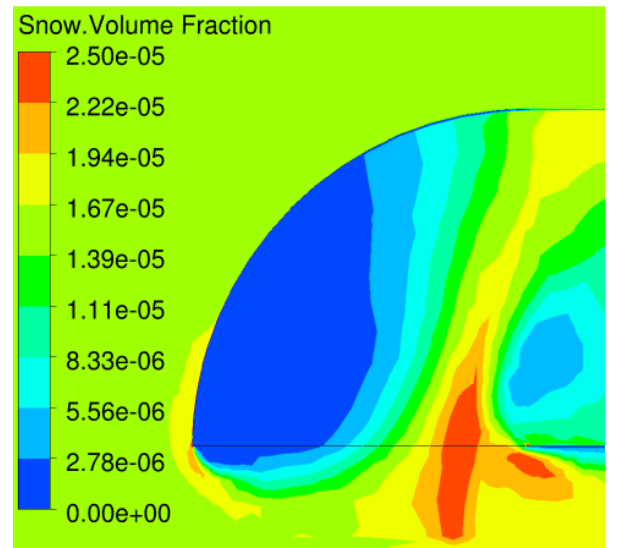

(a) $u_{\text {wind }}=2 \mathrm{~m} / \mathrm{s}$

$\dot{V}=10 \times 10^{3} \mathrm{~m}^{3} / \mathrm{h}$

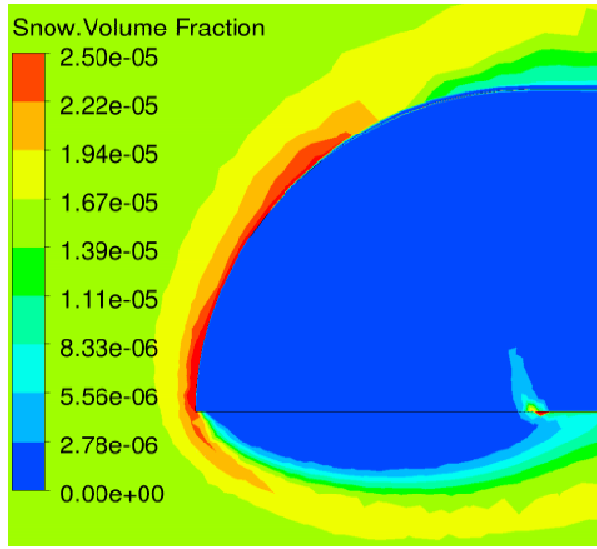

(c) $u_{\text {wind }}=10 \mathrm{~m} / \mathrm{s}$

$\dot{V}=10 \times 10^{3} \mathrm{~m}^{3} / \mathrm{h}$

Fig. 6 Snow volume fraction: elbow, leeward.

of the HVAC decreases the size of the wake. Also the increased wind speed increases the length of the wake.

As shown above, the wake affects the flow across the intake which results in decrease of the effective inlet area. To fulfill the mass conservation and thus keep the given air flow rate at the HVAC outlet, the decrease in flow cross section area has to result in a local increase of air velocity. Such example is show in Fig. 7. For wind velocities of $2 \mathrm{~m} / \mathrm{s}$ and $10 \mathrm{~m} / \mathrm{s}$ and constant flow rate $28 \times 10^{3} \mathrm{~m}^{3} / \mathrm{h}$ the local maximum of air velocity increased approximately from $9 \mathrm{~m} / \mathrm{s}$ to $15 \mathrm{~m} / \mathrm{s}$. This increase of air velocity may increase the amount of infiltrated snow particles.

The behavior of the flow deflector can be clearly described using Fig. 8. The left vertical black line corresponds to the deflector upwind the intake. The plotted vector fields show the wake formed by the

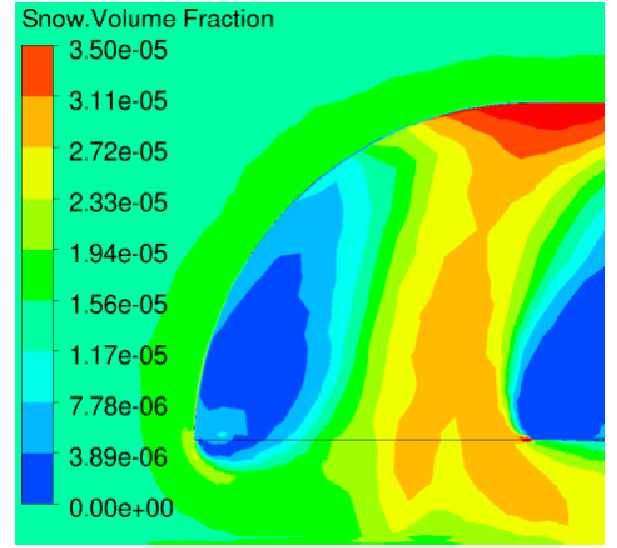

(b) $u_{\text {wind }}=2 \mathrm{~m} / \mathrm{s}$

$\dot{V}=28 \times 10^{3} \mathrm{~m}^{3} / \mathrm{h}$

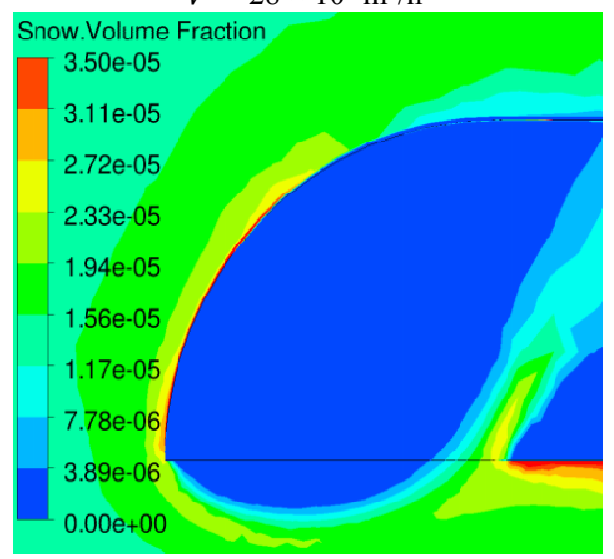

(d) $u_{\text {wind }}=10 \mathrm{~m} / \mathrm{s}$

$\dot{V}=28 \times 10^{3} \mathrm{~m}^{3} / \mathrm{h}$

deflector upstream the intake. Low wind velocity field in Fig. 8, left participates on formation of smaller wake compare to the wake behind the deflector in the case of wind speed of $10 \mathrm{~m} / \mathrm{s}$, as shown in Fig. 8b. This size of the wake may affect the snow infiltration. When the intake is located inside the wake the snow particle is deflected and misses the intake.

\subsection{Study Case 2: Facade Intake}

The section of a domain with a building is shown in Fig. 9. In general, the wind approaching the building facade separates in the stagnation point. The main flow is deflected and when touching the ground the windward wake is formed. The rest of the flow participates on formation of side and leeward wake. As seen, the size and location of the center of each wake is different. The resulting flow direction on a façade surface 


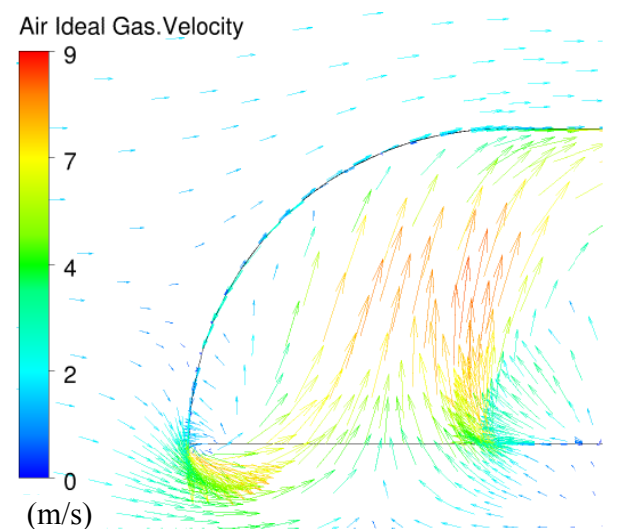

(a) $u_{\text {wind }}=2 \mathrm{~m} / \mathrm{s}$

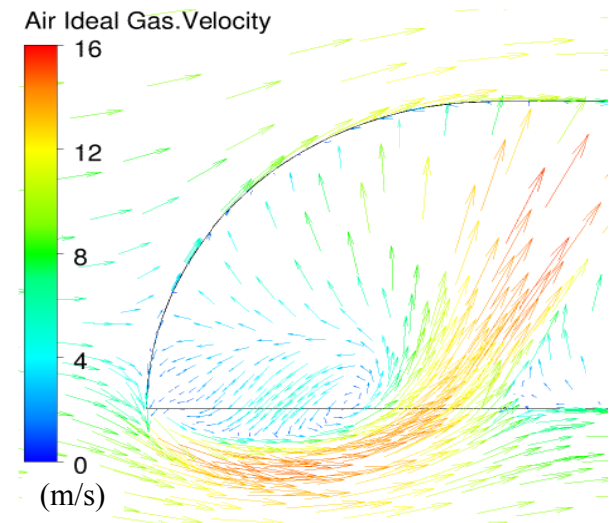

(b) $u_{\text {wind }}=10 \mathrm{~m} / \mathrm{s}$

Fig. 7 Air velocity: elbow, $\dot{V}=28 \times 10^{3} \mathrm{~m}^{3} / \mathrm{h}$.

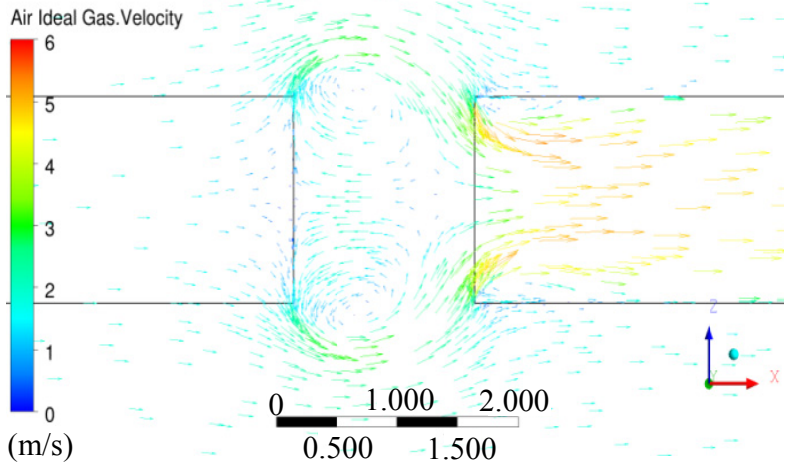

(a) $u_{\text {wind }}=2 \mathrm{~m} / \mathrm{s}$

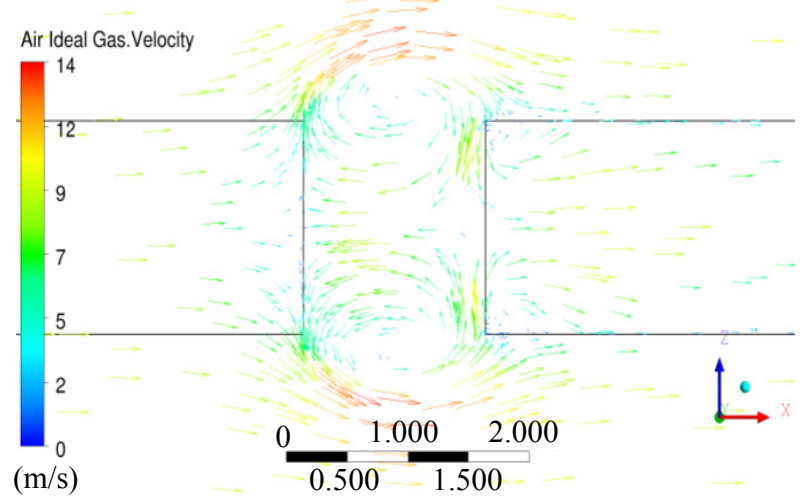

(b) $u_{\text {wind }}=10 \mathrm{~m} / \mathrm{s}$

Fig. 8 Air velocity: free intake with flow deflector.



Fig. 9 Windward and leeward wake of a building.

affects the transport of impinging particles which can consequently influence the snow infiltration.

Using the example in Fig. 9, the overhang shield is located approximately at the stagnation point. Moving the intake upwards would probably result in increased values of IR due to the particle transport from the facade up into the intake. A location beneath the stagnation point and application of overhang shield would stop particle transport into the intake, which would probably result in lower value of IR. The leeward 
wake in this case is simpler with only upward direction of the facade flow. If the snow concentration in the wake is uniform, this would probably result in values of IR independent on the intake location.

The windward situation is shown in Fig. 10. While the free inlet captures most of the snow particles, the overhang shield creates a "shadow" which prevents particle transport into the intake. There also appears to be a high gradient of the snow concentration due to the particles passing the intake without entering and consequently obstructing the facade. Some of these particles enter the intake while the rest follows the main flow. The elbow shield shows different behavior of snow particles. The particles impinging the body of the elbow are deflected downstream and, while leaving the elbow surface immediately captured by the flow going into the intake. The infiltration itself is in this case also increased by the decreased size of the effective area of the intake. The locally accelerated air entrains more snow particles which results in higher values of IR.

As mentioned in results, the application of both overhang and elbow shield comes up with little effect. This can be seen in Fig. 11 where the snow volume fraction in vicinity of any intake is uniform.

\subsection{Exclusion of Screen or Louver in the Study}

Figs. 5, 6, 8 and 10 have shown the significant effect of the intake geometry on snow particle infiltration. Intuitively, the appearance of a screen louver would participate on the overall performance of the intake. Intuitively, it can be assumed that in cases of the leeward free and overhang intake, the effect of screen or louver would be minimal. In contrast, the performance

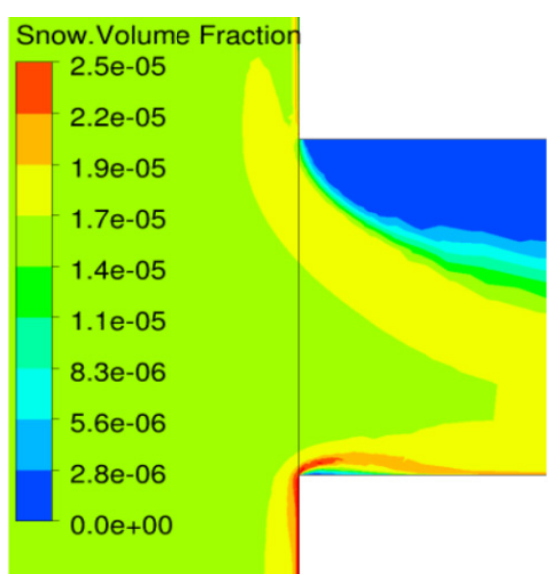

(a) Free

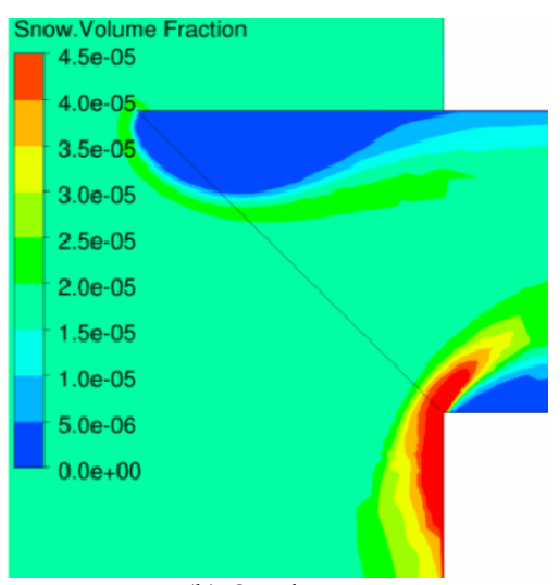

(b) Overhang

Fig. 10 Snow volume fraction: windward façade.

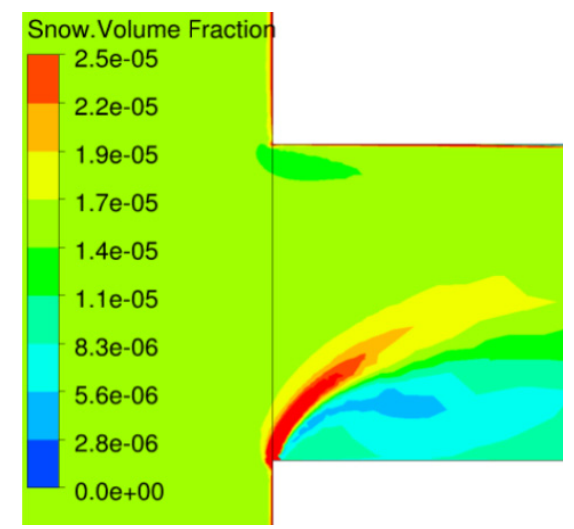

(a) Free

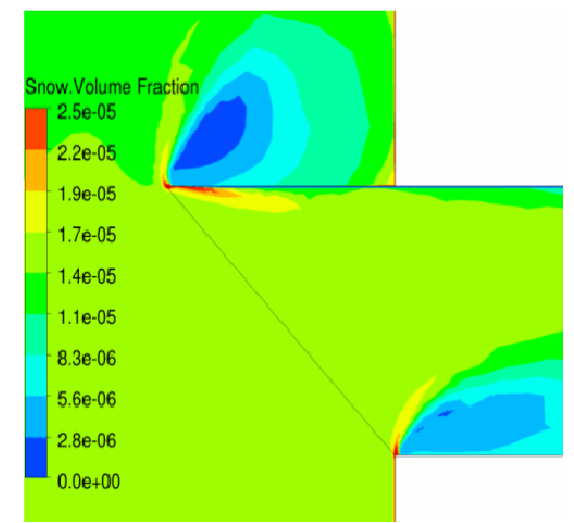

(b) Overhang

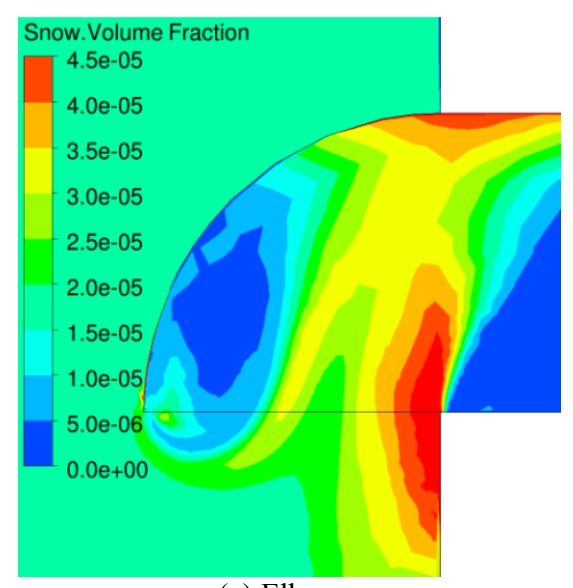

(c) Elbow

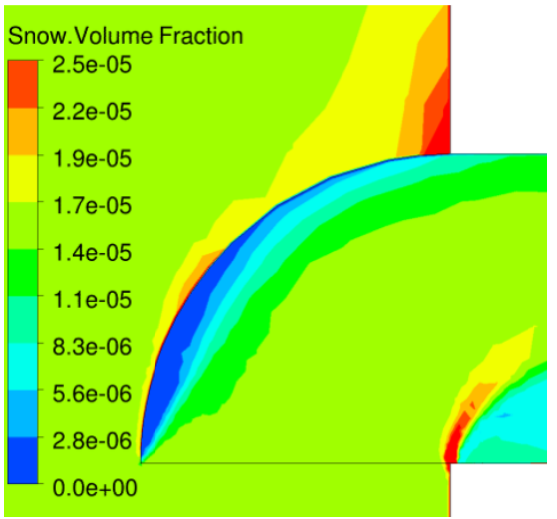

(c) Elbow

Fig. 11 Snow volume fraction: leeward facade. 
Table 5 Daily amount of infiltrated snow.

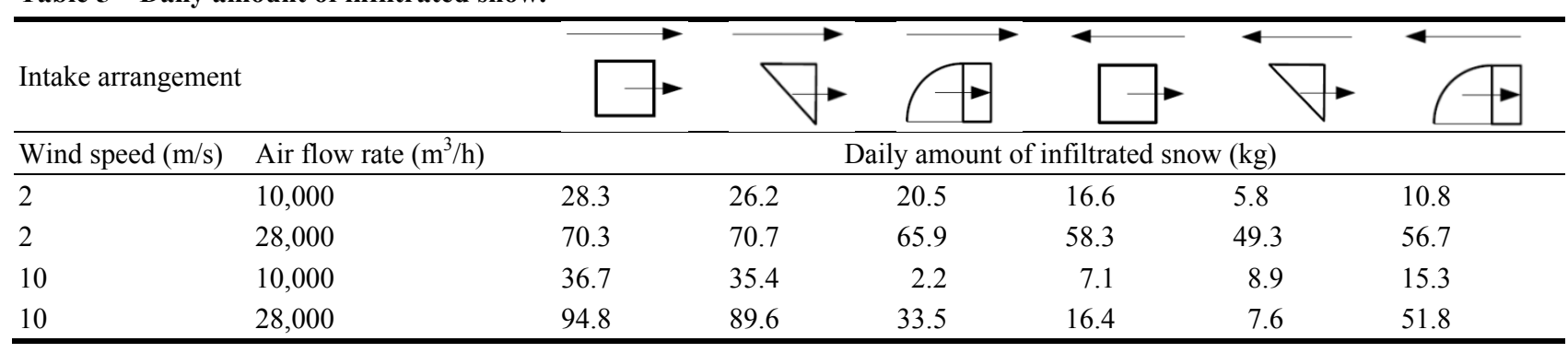

could benefit when installing some screen or louver in front of free and overhang intake in windward arrangement. In case of the elbow, some screen could be effective in both, windward and leeward arrangements. The spacing and sizing of a louver might be important parameter to influence the infiltration as well.

\subsection{Daily amount of Infiltrated Snow}

The total amount of infiltrated snow is a quantity measure which can be used in the design of the HVAC unit. Considering a reference snow precipitation intensity of $0.2 \mathrm{~mm}_{\mathrm{w}} / \mathrm{h}$ and snow particle fall velocity of $0.5 \mathrm{~m} / \mathrm{s}$ the resulting snow concentration of approximately $0.1 \mathrm{~g} / \mathrm{m}^{3}$ can be obtained. Applying this snow concentration and snow event time period of one day, the daily snow infiltration can be calculated using values of IR obtained from the simulations. Daily amount of infiltrated snow for various wind velocities, volumetric flow rates and intake designs are shown in Table 5.

\section{Conclusions}

The simulation results show the effect of various intake designs, HVAC operating conditions and wind conditions on overall snow infiltration into an intake. It can be concluded that the magnitude and direction of the wind influences snow infiltration significantly. The position of the intake downwind shows significant decrease in the amount of infiltrated snow. If the intake is faced upwind, the flow deflector shows positive effect on the amount of infiltrated snow. Both tested intake designs, overhang and elbow shields have advantages and disadvantages depending on wind conditions and overall aerodynamics. While the elbow shield showed higher efficiency for windward positions, the overhang was more efficient in leeward position.

It should be also stated that all cases were simulated considering artificial snow. The common properties of natural snow differ and therefore the obtained simulation results may change. However, it is believed that the described behavior remains. Due to the variety of properties of natural snow, wind conditions and the wind tunnel or outdoor experiments and measurements are needed to validate the model for common conditions.

Also, it is important to notify that the intake was studied without any screen or louver. As shown in figures before, the intake geometry influences the infiltration. Thus any additional screen or louverwould participate on the overall infiltration as well.

The approach to estimate the amount of snow infiltration can be used in design process of HVAC systems, e.g. drainage, serviceability, etc.. Also, based on such model, tables of RSRE of an intake equipped with specific screen or louver could be defined, which would simplify the design process considering the risk of high snow infiltration.

\section{References}

[1] S.O. Hanssen, HVAC-The importance of clean intake section and dry air filter in cold climate, Indoor Air 14 (2004) 195-201.

[2] V. Asikainen, P. Pasanen, The prevention of the snow entrance to the HVAC-Systems, in: Proceedings of Clima 2007 Well-Being Indoors, Helsinki, Finland, June 


\section{Conditioning Intake: A Numerical Study}

11-14, 2007.

[3] T.K. Thiis, P. Delpech, Measurements of snow penetration in to ventilation openings in buildings, in: Snow Engineering VI, Whistler, BC, Canada, June 1-5, 2008.

[4] T.K. Thiis, P. Barfoed, P. Delpech, A. Gustavsen, V. Hofseth, S. Uvsløkk, et al., Penetration of snow into roof constructions-Wind tunnel testing of different eave cover designs, Journal of Wind Engineering and Industrial Aerodynamics 95 (2007) 1476-1485.

[5] National Building Code of Finland, D2 "Indoor Climate and Ventilation of Buildings", 2003.

[6] EN 13779, Ventilation for Non-residential
Buildings-Performance Requirements for Ventilation and Room Conditioning Systems, 2007.

[7] M. Mellor, Blowing Snow, U.S. Army Materiel Command, Cold Regions Research and Engineering Laboratory, Hanover, New Hampshire, 1965.

[8] L.S. Fan, C. Zhu, Principles of Gas-Solid Flows, Cambridge University Press, Cambridge, 1998.

[9] J. Potac, T.K. Thiis, Numerical modeling of snow infiltration into ventilation openings, in: Proceedings of the Fifth International Symposium on Computational Wind Engineering, Chapel Hill, NC, USA, May 23-27, 2010. 